\title{
Nano-scale Advances in Catalysis and Energy Applications
}

Yimin Li and Gabor A. Somorjai*

Department of Chemistry and Lawrence Berkeley National Laboratory University of California, Berkeley

*To whom correspondence should be addressed. Email: Somorjai@berkeley.edu

\begin{abstract}
In this perspective, we present an overview of nanoscience applications in catalysis, energy conversion, and energy conservation technologies. We discuss how novel physical and chemical properties of nanomaterials can be applied and engineered to meet the advanced material requirements in the new generation of chemical and energy conversion devices. We highlight some of the latest advances in these nanotechnologies and prowide an outlook at the major challenges for further developments.
\end{abstract}

\section{Introduction}

We just completed the second edition of the textbook, "Introduction to Surface Chemistry and Catalysis", 16 years later after the first edition.[1] It was an opportunity to take stock of the surface science and catalysis fields where the most significant developments accurred in recent years. Among the fields that experienced impressive advances, nanoscience and nanotechnology have been 
undergoing the most explosive growth. Nanotechnology refers to techniques capable of design, synthesis, and control of nanomaterials that offer advanced material properties for novel applications.

Nanomaterials were not totally unfamiliar within these fields in the past. For example, heterogeneous catalysts in the form of nano-size transition metal particles dispersed on microporous supports have been applied to chemical conversion technologies for many decades. The tremendous advantes in modern nanotechnology are reflected in our expanded ability to design and control nanomaterials, their size, shape, chemical composition, and assembly structure for advanced applications. [2-4]

This perspective discusses the technical foundation for nanoscience development: synthesis approaches and characterization techniques. We also discuss the latest advances in nanomaterial applications for heterogeneous catalysis, energy conversion, and energy conservation technologies.

\section{Nanostructure Synthesis and Characterization}




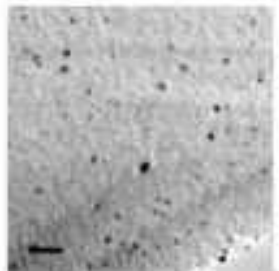

$1.73 \pm 0.26 \mathrm{~nm}$

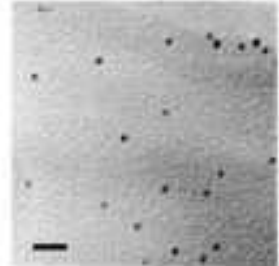

$2.48 \pm 0.22 \mathrm{~nm}$

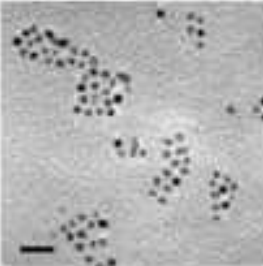

$2.80 \pm 0.21 \mathrm{~nm}$

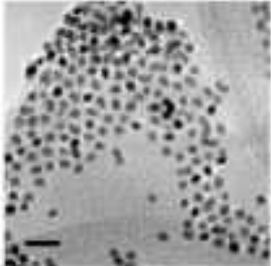

$3.39 \pm 0.26 \mathrm{~nm}$

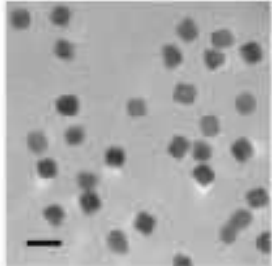

$7.16 \pm 0.37 \mathrm{~nm}$ $\mathrm{K}_{2} \mathrm{PtCl}_{4} \stackrel{\mathrm{C}_{14} \mathrm{TABr}}{\underset{50^{\circ} \mathrm{C}}{\longrightarrow}}\left(\mathrm{C}_{14} \mathrm{TA}^{+}\right)_{2} \mathrm{PtBr}_{4}{ }^{2-}$

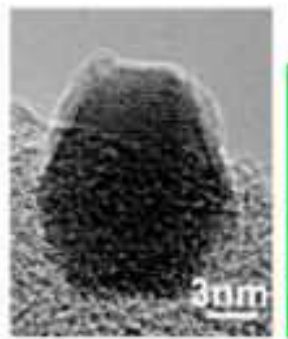

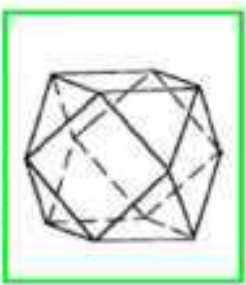

Cuboctahedra

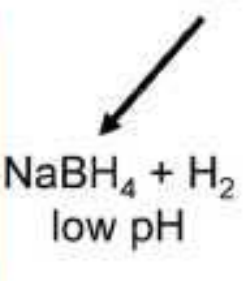

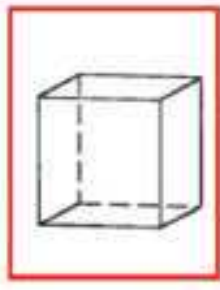

Cubes $\{100\}$

Figure 1 The size and shape controlled Pt nanoparticles prepared by the colloid-chemistry controlled method.

Well-controlled synthesis of nanomaterials and nano-scale characterization enable us to unambiguously correlate the structural properties with the physical, chemical, and biological properties of nanomaterials, which form the core of nanoscience research. A basic requirement for nanomaterial synthesis is the uniformity of the final product in size, shape, and chemical composition. Recently, many synthesis approaches have been developed to produce high quality nanoparticles, nanorods, nanowires, or other nanostructures using metals, semiconductors, and oxides.[5-15] An example (Figure 1) is the shape- and size-controlled Pt nanoparticles synthesized by the colloid chemistry controlled approach.[16] These nanoparticles can be readily deposited as films or dispersed into a mesoporous oxide support for studying size and shape dependence of catalytic properties. $[17,18]$ 
Due to the high spatial and chemical resolution requirements, a combination of techniques is usually applied to characterize nanomaterials. Commonly used characterization techniques for nanomaterials are listed in Table 1. Many of them, which are indicated by asterisks in Table 1, have been developed and applied to characterize the properties of nanomaterlals under working conditions and provide the molecular level knowledge for further performance optimizations.

Table 1 Commonly used tharacterization techniques for nanomaterials

\begin{tabular}{|l|l|}
\hline \multicolumn{1}{|c|}{ Techniques } & \multicolumn{1}{c|}{ Properties characterized } \\
\hline Transmission Electron Microscopy *(TEM) & size, shape, and crystallinity \\
\hline X-ray Diffraction* (XRD) & crystal structure \\
\hline UV-Vis-nIR Spectroscopy* & light absorption and stattering \\
\hline Photoluminescence Spectroscopy* (PL) & light emission \\
\hline X-ray Photoelectron Spectroscopy* (XPS) & chemical composition \\
\hline Chemisorption, Physisorption & surface area \\
\hline Scanning Electron Microscopy (SEM) & shape, and assembly structure \\
\hline Small Angle X-ray Scattering* (SAXS) & $\begin{array}{l}\text { characteristic distances of partially ordered } \\
\text { nanomaterials }\end{array}$ \\
\hline Energy Dispersive X-ray Analysis (EDX) & chemical composition \\
\hline Scanning Tunneling Microscopy* (STM) & shape, size, and surface structure \\
\hline Atomic Force Microscopy* (AFM) & shape, size, and work function \\
\hline Ultraviolet Photoelectron Spectroscopy (UPS] & electron valence band \\
\hline X-ray Emission Spectroscopy* (XES) & electron band gap \\
\hline $\begin{array}{l}\text { Near-edge X-ray Absorption Fine Structure* } \\
\text { (NEXAFS) }\end{array}$ & chemical composition \\
\hline Extended X-ray Absorption fine Structure *(EXAFS) & chemical composition and bonding environment \\
\hline
\end{tabular}

\section{Nanocatalysis}

A catalyst is an entity which accelerates a chemical reaction without being consumed in the process.

This ability is usually referred to as the activity of a catalyst. For a chemical reaction with multiple possible products, a catalyst may promote the production of one of the products, called catalyst selectivity. Catalysis plays an important role in the technologies for transportation fuel production from 
fossil fuels or alternative energy resources, bulk chemical production, and pollution control, where efficient and selective chemical conversion processes are of great concern. The major gaal for catalysis research in this century is to design new catalysts with desirable activity and higher selectivity in order to allewate energy and process requirements for separation and purfication using current technologies bassed on fossil raw materials, and to protect our environment by reducing the need for disposal of waste chemicals.[19]

Heterogeneous, homogeneous, and enzymatic catalysts are nanoparticles. Heterogeneous catalysts promote reactions at the active sites on their surfaces, so they are usually in the form of nanoparticles with a large concentration of surface active sites. Advances in nanoscience provide opportunities for developing next-generation catalytic systems with high activities for energetically challenging reactions, high selectivity to valuable products, and extended life times. $[4,20]$ The development of nextgeneration nanocatalwsts relies on surface science techniques which identify and characterize surface active sites at the atomic scale[21] and synthesis approaches which are capable of producing stable surface active sites through controlling the size, shape, and chemical composition of nanocatalysts.

\section{Highly-Active Nanocatalysts}

The best example for demonstrating the exceptional catalytic activity of nanomaterials is a catalyst with gold nanoparticles in the $5 \mathrm{~mm}$ regime dispersed on a titania support. This catalyst exhibits high activities for hydrocarbon epoxidation and $\mathrm{CO}$ oxidation at room temperatures.[22] It has been suggested that the quantum confinement effects change the electronic structure of this noble metal and lead to the unusual catalytic activities observed. [23, 24] This discovery has spurred extensive research efforts in searching novel nanocatalysts for the important catalytic reactions with low reactivity, such as activation of saturated hydrocarbons in reforming reactions $[25,26]$, oxygen reduction reactions in fuel cells[27], 
and lingo-cellulose biomass hydrolysis[28-32]. For example, it has been reported that small, charged metal clusters exhibit facile activation and dehydrogenation of methane molecules. [33, 34]

\section{Highly-Selective Nanocatalysts}

Highly-selective catalysts may help reduce the energy consumption required for product separation and waste disposal processes in chemical industries. The development of alternative energy resources also relies on highly-selective catalysts. The selective conversion of biomass-derived carbohydrates to liquid fuels and valuable chemicals is a key step in biomass conversion. [35-39] Many molecular level factors affecting catalytic selectivity have been identified in our laboratory using surface science studies during the few last decades, which allow for nanotechnology to design and engineer highly-selective catalysts.[21]
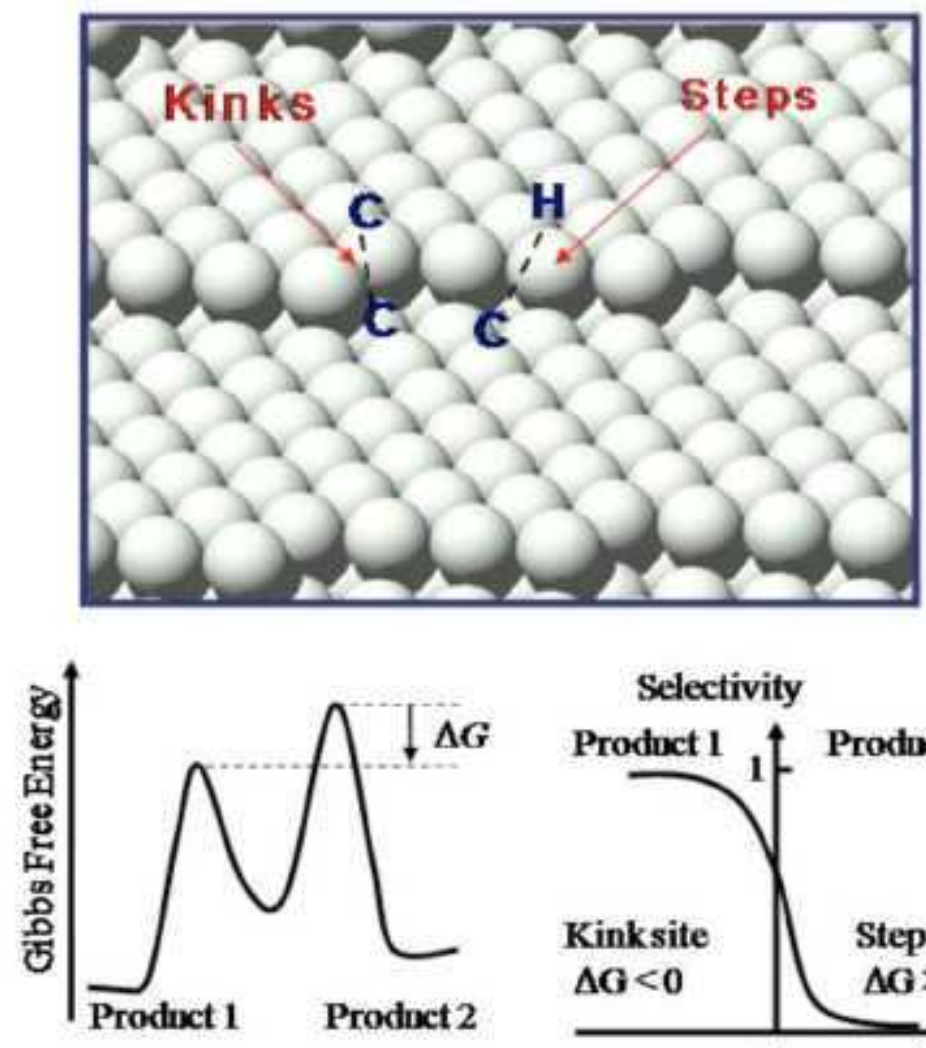

Selectivity

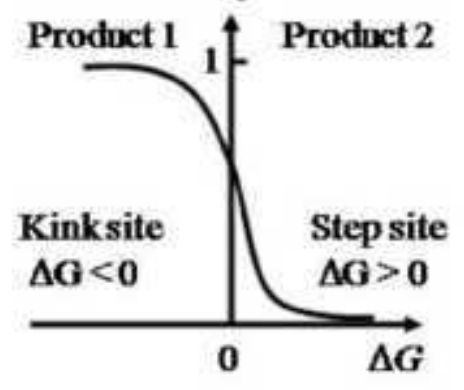


Figure 2 The upper panel: the model kinked Pt surface (the upper panel). The $\mathrm{C}-\mathrm{C}$ bond and $\mathrm{C}-\mathrm{H}$ bond are dissociated at the kink and step site, respectively. The lower left panel: the schematic free energy potential surface for two-pathway reaction. Product 1 is formed by breaking the $C-C$ bond, and Product 2 is formed by breaking the C-H bond. The activation barrier for product 1 is lowered at the kink site, which leads to the difference in selectivity between the step and kink sites, as shown in the lower right panel.

For a multiple-path catalytic reaction, the rate-determining steps for different products usually occur at different active sites on the catalyst surface. Consider a catalytic reaction involving a cydic. hydrocarbon reactant (Figure 2), the scission of the $C-C$ bonds leads to the ring opening product [product 1); while, the dissociation of a $\mathrm{C}-\mathrm{H}$ bond gives a dehydrogenation product (product 2]. The ratio of product 1 to product 2 produced at a given surface site is controlled by the relative heights of the Gibbs free energy barriers for the two products. At the step sites on platinum surfaces, the scission of $C$ $H$ bond accurs more readily than that of the $C-C$ bond, which leads to a higher probability for forming the dehydrogenation product. At the $k$ Ink sites, the breaking of the $C-C$ bond becomes more facile and the increase of the ring-opening product is expected. From this simple plcture, the selectivity of heterogeneous catalytic reactions is ultimately determined by the relative concentrations of active sites for different reaction pathways. For nanopartide catalysts, the concentration of active sites is determined by the size and shape of the nanoparticles. Advances in nanoparticle swnthesis enable the precise control of surface active sites by manufacturing mono-disperse and shape-controlled catalysts. An example is shown in Figure 3, where the selectivity of pyrrole hydrogenation over Pt nanoparticles exhibits both size and shape dependence. $[40,41]$ The selectivity change is induced by the surface structure change of the nanocatalysts with different sizes and shapes. 
(a)
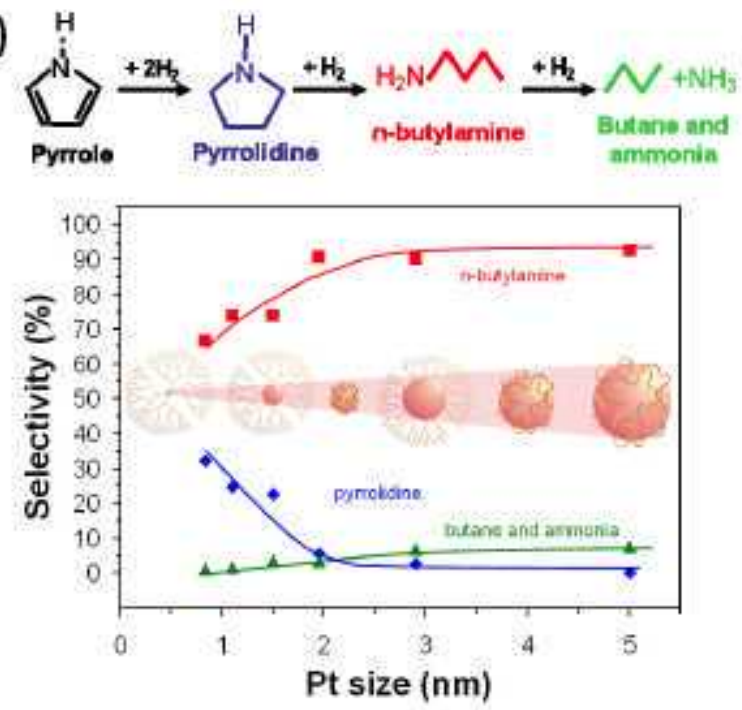

(b)

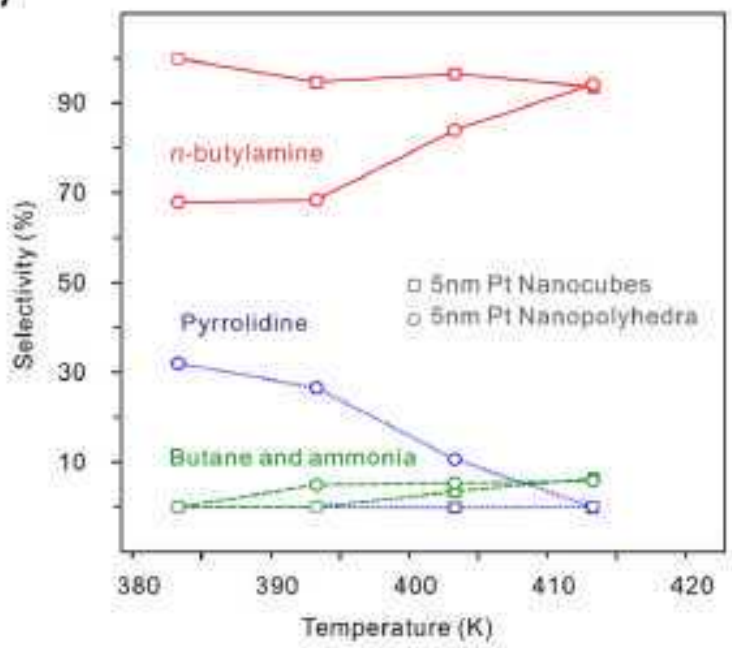

Figure 3 (a) The nanoparticle size dependence of the selectivity of pyrrole hydrogenation under the reaction condition: 4 Torr pyrrole, 400 Torr $\mathrm{H}_{2}, 413 \mathrm{~K}$. Small nanoparticles exhibit high selectivity to pyrrolidine. (b) The nanoparticle shape dependence of the selectivity of pyrrole hydrogenation under the conditions: 4 Torr pyrrole, 400 Torr $\mathrm{H}_{2}$. At relatively lower temperatures, nanopolyhedra particles have a higher selectivity to pyrrolidine than nanocubes.

An important class of selective catalysts are bimetallic alloys that provide surface active sites with special atomic arrangements of metal components.[42] Recently, this field has been revolutionized by the emergence of rational catalyst design at nano-scale. $[43,44]$ High-throughput, computer-based screening provides the elements and atomic arrangement of alloy candidates that may have optimal catalytic properties. Then, nanoalloys are synthesized and tested. The successful synthesis of alloy catalysts with intended composition relies on the fact that the size reduction of alloy particles usually results in lowering the immiscible gap. [45] Following this approach, a $\mathrm{Ni}_{1} \mathrm{Zn}_{3}$ alloy catalyst has been discovered with a higher selectivity for partial hydrogenation of acetylene.[46] 
In a more recent study, in-situ X-ray photoelectron spectroscopy has been applied to monitor the surface segregation of bimetallic nanoparticles under reaction conditions. [47] It has been observed that the bimetallic composition on nanoparticle surfaces alternates upon switching the chemical gas environment between ox[dizing and reducing condit/ons. This new insight may lead to the development of "smart" catalysts whose surface structure advantageously depends on the reaction environment.

\section{Catalyst Support Nanomaterials}

Catalyst supports are usually made of high-surface-area micro/mesoporous oxides or carbon nanomateria|s. These support materials stabilize metal catalysts against sintering at high reaction temperatures. Some support materials, especially, reducible oxides can also promote the activity and selectivity of active metal catalysts. Many innovations have been made in designing nanostructured support materials. An example is the significant thermal stability enhancement of a core-shell catalyst in which the Pt nanoparticle is coated with a thin laver of mesoporous silica.[48] Another interesting example is using carbon nanotube-inorganic oxide hybrid nanoparticles as a support for phase-transfer reactions (reactants and products are in different phases) in order to simplify the separation and purification processes. [35, 49] These hybrid nanopartides are amphiphilic and stabilize water-oil emulsions. The metal catalysts, immobilized on the hybrid support, preferentially stay at the water-oil interface, where catalyt|c phase-transfer reactions happen. The emulsions are extremely stable and can be easily separated from the biphasic liquid by a simple fi|tration. The rectycled hybrid nanoparticles can be reused without any special treatment. It has been demonstrated that the hybrid materials can catalyze biphasic hydrodeoxygenation and aldol condensation reactions.

\section{Nanotechnology in Energy Applications}

At present, developing efficient and "clean" energy technologies is an urgent task and is crucial to the long-term energy and environmental security of our society.[50] Energy conversion and transport in 
nanomateria|s differs significantly from bulk materials because of classical and quantum size effects on energy carriers such as photons, phonons, electrons, and molecules. Nanoscience for energy applications is now focused on tailoring these nano-scale effects for efficient energy technologies such as photovoltaits, photochemical solar cells, thermoelectric, fuel cells and batteries etc. For example, the efficient light absorption to generate charge carriers in a solid occurs at the scale of several hundreds of nanometers (wavelength of light). The mean free path of the excited charge carrier is much shorter than the wavelength of light. In order to achieve efficient photon absorption and collection of excited charge carriers in a photowoltaic device, an optimal design should be low-dimensional nanostructures, such as nanowires of semiconductors, in which at least one dimension is larger than the wavelength of light, and another dimension shorter than the mean free path of charge carriers. $[8,51]$

\section{Solar Energy Conversion}

Solar energy is the most obvious "clean" and renewable alternative energy source (under ideal conditions, radiation power on a horizontal surface is $1,000 \mathrm{~W} \mathrm{~m}^{-2}$ y. [52] Photovoltaic cells convert the photon energy directly to electriclty by separating the exdted electron-hole palrs in photovoltaic materials. Photoelectrochemical cells use the excited electrons and holes to catalyze redox reactions which may split water or $\mathrm{CO}_{2}$ to generate fuels. Currently, photowoltaic and photoelectrochemical cells have not made a strong contribution to the energy supply because of their low conversion eff[ciencles.

Sun light Horvesting. Nanostructured photowoltaic materials can significantly improve the efficiency of solar energy based devices. In order to efficiently absorb sun light over the entire spectrum range, several approaches, including embedding quantum dots[53] or quantum wells[54] into the light absorption layer, using dye-sensitized semiconductor nanostructures [55, 56] and utilizing multiple exciton generation (MEG) observed in the semiconductor nanocrystallines [57], have been proposed. MEG is one of the approaches promising extremely high efficiency to overcome the performance-cost 
issue. In the MEG process, absorption of a single photon produces multiple electron-hole pairs (excitons) and hence the internal quantum efficiency $(\mathrm{IQE})$ for conversion photons into charge carriers may exceed $100 \%$. [57] It was first suggested by Nozik that the efficiency of MEG might be enhanced in nanoscale semiconductor particles due to reduced rates of intraband relaxation and enhanced Coulomb interaction between electron-hole pairs.

Charge Separation. Once electron-hole pairs form from an excited photon, they have a finite life time before recombination. In order to separate electron and hole efficienty, various heterostructures consisting of nanomaterials such as thin films, nanowire[51] and dye-senitized nanoparticles[55, 58] have be designed and synthesized. Dye-senitized solar cells offer an inexpensive route to the development of highly efficient photovoltaic devices.[56] By attaching sensitizer to a semiconductor nanocrystalline, such as $\mathrm{TiO}_{2}$ nanoparticles, the photon-excited electrons can be efficiently transferred onto the $\mathrm{TiO}_{2}$ conduction band, which increases light harvesting efficiency by reducing charge recombination.

Chemical Fuel Production. There are several extra factors other than the light-to-charge conversion harvesting that limit the efficlency of photoelectrochemical $\{\mathrm{PEC}$ cells. [59, 60] A PEC cell is a photocatalytic system which catalyzes two redox reactions using photon generated electron-hole pairs: one reacting with the holes at the surface of an anode and the second reacting with the electrons at the surface of a cathode. For the semiconductor-based PEC cells, the semiconductor must satisfy the following requirements: 1) The band gap of the semiconductor must be greater than the equilibrium potential difference between the two redox reactions. 2) The conduction band energy level must be higher than the potential of the redox reaction on the cathode and the valence band energy level must be lower than the potential of the redox reaction on the anode. 3) The surface area of the electrodes must be large enough to provide a high conversion rate, since the rodox reactions occur on the surfaces. 
There are two most valuable, but challenging, photocatalytic energy conversion processes currently under intensive research: electrolysis of water to hydrogen and oxygen, and conversion of carbon dioxide and water vapor into hydrocarbon fuels. [61-63] Nanostructured electrodes provide large surface area for photocatalyzed reactions. By band engineering using controlling size, shape, themical composition, and heterojunction of semiconductor materials, nanomaterials provide the opportunity to achieve high efficiencies for sunlight to charge conversion and chemical conversions at the electrode surfaces at the same time. $\left[51_{x} 64\right]$ It has been reported that the nanocomposite $\left(G a_{1-x} Z n_{x}\right)\left(N_{1-x} O_{x}\right]$ photocatalysts with $\mathrm{Rh}_{2-\gamma} \mathrm{Cr}_{\mathrm{r}} \mathrm{O}_{3}$ as cocatalyst exhibits an apparent quanturn efficiency for overall water splitting as high as $5.9 \%$ under a visible light of $420-440 \mathrm{~nm}$. [65]

\section{Fuel Cells and Batteries}

Fuel cells and batteries, such as polymeric-electrolyte-membrane fuel cells, solid-oxide fuel cells, and lithium batteries, are electrochemical systems for conversion between chemical energy and electricity. $[66,67]$ They consist of an anode and a cathode, separated by an electrolyte. A palr of reduction and ox/dation reactions on the electrode surfaces results in electric current generation. Applications of nanomaterials may significantly improve the efficiency of full cells and the energy storage density of batteries. One common factor limiting the efficiency of electrochemical systems is the Ion conductivity of the electrolyte. In the literature, it is shown that ion|c transport can be dramatically enhanced by using nanostructured composites. These phenomena, known as nanolonics effects, have been attributed to the fast ion transport in the space charge layer at the heterogeneous interface between an insulation material with high surface charge density and an ion conducting material.[68, 69] In a nanostructured composite, the reduction of the thickness of the space charge laver increases surface charge density, and the closely-compacted structure also makes the nanoscale space charge zones connected to each other to provide ion transport pathways. For example, composites In which Lil is infiltrated in mesoporous $\mathrm{Al}_{2} \mathrm{O}_{3}$ may exhibit conductivities 100 t/mes higher than that of pure $\mathrm{LIl}$ at 
room temperature. [70] This ion conductivity enhancement has also been observed a non-aqueous liqquid electrolyte after the addition of $\mathrm{SiO}_{2}$ nanoparticles.[71]

The use of nanomaterials on the electrodes of electrochemical cells mav enhance the charge storage capacity of barrlers and the reaction rates of redox reactions in fuel cells. $[72,73]$ Nanostructured composites may have a very high charge storage capacity due to the nanolonics effect at interfaces. [68, 69] For example, nanostructured $\mathrm{L}_{2} \mathrm{O} / \mathrm{Ru}$ composites show high $\mathrm{L}^{*}$ storage capacity which is neither observed in pure $\mathrm{L}_{2} \mathrm{O}$ nor pure $\mathrm{Ru}$. In carbon-based electrodes, nanomaterials, such as carbon nanotubes, carbon nanohorns, etc., provide high surface area supports for metal catalysts and excellent conductivity for charge transport. $[74,75]$

\section{Nanotechnologies for Energy Conservation}

Thermoefectric Devices. Thermoelectric materials may efficiently convert waste heat generated by combustion engines to electricity, which improves the overall energy efficiency of engines. There are two required propertles for a highly efficient thermoelectric material: 1) a high charge carrier diffusion current under a temperature gradient in the material with minimized Joule heating, 2) a low thermal conductivity so that a large temperature gradient can be attained in the material. For pure bulk materials, these two properties are difficult to optimize at the same time because the charge carrier, such as an electron, is also a thermal energy carrler. The increase of carrler density inevitably leads to an increase in the thermal conductivity. For many years, the energy efficlencies of pure bulk material based thermoelectric devices have remained at $<5 \%$, far below that of conventional thermal power generators.

Nanostructures and nanostructured materials hold the promise of more efficient themoelectric energy conversion. [76] The basic idea comes from the observation of a disparity between the mean free path lengths of the dominant charge carrier and the thermal energy carrler, such as phonon in 
semiconductor materials. If the characteristic length of a nanomaterial is in between the two mean free path lengths, it may be possible to optimize one of the transport properties while leaving the ather intact. The improvement of energy conversion efficiency has been demonstrated by several nanomaterials including the PbTe-based quantum dot superlattice system[77], the $\mathrm{Bi}_{2} \mathrm{Te}_{3}-\mathrm{Sb}_{2} \mathrm{~T} \mathrm{e}_{2}$ twodimensional superlattice system[78], and șilicon nanowire systems[51]. The enhanced efficiencles have been attributed to the impedance of the flow of heat by phonon scattering at the interfaces in these nanomaterials.

Efficient Lighting Device. Lighting uses about $20 \%$ of the total electricity generated. Development of advanced lighting devices with high luminous efficiency will have significant impact on energy conservation. [79] In addition to high efficiency, a light source must be capable of rendering the true colors of an object, that is, the emitted light must cover a signifitant portion of the visible spectrum range. The light-emitting diode (LED) is one of the promising lighting sources currently under extensive research. The high efficiency and goad rendering properties require that a semiconductor material used for LED applicatlons must have high crystallinity and a tunable band gap.[80]

As quantum dot size decreases, quantum confinement causes the band gap to Increase and this leads to blue-shifted light emission. [81] It has alsa been demonstrated that the composition of singlecrystalline $\ln _{x} \mathrm{Ga}_{1-k} \mathrm{~N}$ nanowires can be tuned across the entire compositional range from $x=0$ to 1 . The photoluminescence emission of these nanowires covers a wide spectrum range from near-ultraviolet to near-infrared.[82] Due to the crystal quality and the tunable emission, semiconductor nanostructures have been actively invest/gated for the development of light em[tting materials.

Nanotribology. Friction is responsible for a large portion of energy wasted in modern machinery, such as internal combustion and aircraft engines, gears, etc. Development of new lubrication materials is a major task for tribology, the science and technology of two interacting surfaces in relative motion.[83- 
86] Conventional solid lubricants are thin films of graphite and the metal dichalcogenides $M X_{2}$ (where $M$ is molybdenum or tungsten and $X$ is sulphur or selenium). These materials are characterized by weak interatomic interactions between their layered structures, allowing low-strength shearing. Using these materials in fullerene-like hollow nanoparticle form can further lower the friction and enhance the chemical inertness in humid environments. $[87,88]$ The hollow cage structure imparts elasticity and allows the particles to roll rather than to slide. The presence of curved crystal surfaces prevents oxidation and preserves the layered structure inside the nanoparticles.

\section{Outlook}

The novel physical and chemical properties of nanomaterials promise many advanced applications in development of new energy and chemical conversion technologies. In this perspective, we have discussed how nanomaterials can make significant contributions to the technologies in catalysis, solar energy harvesting, fuel cells and batteries, and energy conservation.

Accompanying these exciting opportunities, there are also major challenges before prom[s[ng nanotechnologies will replace conventional technologies. In nanocatalysis, achieving $100 \%$ selectivity, as seen in enzyme catalytic reactions, îs still a challenging task. In several fields, such as photoelectrochemical cells for water and $\mathrm{CO}_{2}$ splitting, and thermoelectric devices, the low efficiency of nanodevices is of major concern at present. One of the major challenges in many nanotechnology applications is the development of large-scale and well-controlled synthesis and assembly approaches for manufacturing complex and durable nanostructures. All these thallenges call for an atomic level understanding of physical and chemical processes within nanostructures.

It is of great importance to develop in situ experimental techniques for characterizing nanomaterials under working conditions. For example, transmission electron microscop $\gamma[89]$ and $X$-ray 
absorption spectroscopy[90] can monitor the growth of nanoparticles in solutions. The understanding of nanoparticle growth mechanisms may lead to large-scale and well-controlled nanoparticle synthesis processes. $[91,92]$ Techniques, such as $X$-ray photoelectron spectroscopy, sum-frequency generation vibrational spectroscopy, and scanning tunneling microscopy, can be applied to identify active sites on catalyst surfaces and to study the deactivation of active sites under reaction conditions. [21] This acquired knowledge is crucial for designing new nanocatalysts with high activity, high selectivity, and extended catalytic life time.

Due to device complexity in nanotechnologies, theoretical modeling is now playing an increasingly important role in device design. A good theory may help with understanding and predicting new properties associated with nanomaterials. Multi-scale device modeling can estimate the theoretical limit on the efficiency of each component and identify the overall efficiency limiting factors. Rational design that combines theoretical modeling with advanced experimental techniques will significantly shorten the R\&O cycle of new nanotechnologies.

\section{Acknowledgments}

This work was supported by the Director, Office of 5cience, Office of Basic Energy 5ciences, of the U.S. Department of Energy under Contract No. DE-AC02-05CH11231.

\section{References}

1. Somorjai, G.A. and Y. Li, introduction to Surface Chemistry and Catalysis. 2th ed. 2010, Hoboken, New Jersey: John Wiley \& Sans, Inc.

2. Linkov, 1, Nanomaterials. 2008, New York: Springer.

3. Vollath, D., Nanomaterials : an introduction to synthesis, properties and application. 2008, Weinheim: Wiley-VCH. ix, $352 \mathrm{p}$. 
4. Somorjai, G.A., F. Tao, and J.Y. Park, The nonoscience revolution: Merging of colloid science, catolysis and nanoelectronics. Topics in Catalysis, 2008. 47(1-2): p. 1-14.

5. Terrones, M., Science and technology of the Twenty-First Century: Synthesis, properties, and applications of carbon nanotubes. Annual review of materials research, 2003. 33: p. 419$501 \mid x+654$.

6. Zhao, O.Y, et al., Topolagical construction of mesoporous materials. Current Opinion in Solid State \& Materials Science, 1998. 3(1): p. 111-121.

7. Muray, C.B., C.R. Kagan, and M.G. Bawendi, Synthesis and charocterization of monodisperse nanocrystals and close-packed nanocrystol assemblies. Annual Rewew of Materials Stience, 2000. 30: p. 545-610.

8. Xīa, Y.N., et al., One-dimensional nonostructures: Synthesis, characterization, and applications. Advanced Materials, 2003. 15:(5): p. 353-389.

9. Law, M., J. Goldberger, and P.D. Yang, Semicondutor nonowires and nonotubes. Annual Review of Materials Research, 2004. 34: p. 83-122.

10. Yin, Y.D., et al., Formation of hollow nanocrystals through the nanoscale Kirkendall Effect. Science, 2004. 304(5671): p. 711-714.

11. Rioux, R.M., et al., High-surface-area catalyst design: Synthesis, characterization, and reaction studies of platinum nanopartictes in mesoporous SBA-15 silica. Journal of Physical Chemistry B, 2005. 109(6): p. 2192-2202.

12. Yin, Y. and A.P. Alivisatos, Colloidd nonocrystol synthesis and the organic-inorganic interface. Nature, 2005. 437(7059): p. 664-670.

13. Zhang, Y.W., et al., One-step polyol synthesis ond fongmuir-blodgett monolayer formotion of size-tunable monodisperse rhadium nanocrystais with cotalytically active (111) surface structures. Journal of Physical Chemistry C, 2007. 111(33): p. 12243-12253.

14. Huang. W., et al., Dendrimer templated synthesis of one nanometer Rh and Pt particies supported an mesoporous silica: Cotalytic activity for ethylene and pyrrole hydrogenation. Nano Letters, 2008, 8(7): p. 2027-2034.

15. Somorjai, G.A. and J.Y. Park, Colloid Stience of Metal Nonoporticle Catalysts in 20 and 30 Structures. Challenges of Nucleation, Growth, Compasition, Porticle Shape, Size Control and Their influence on Activity and Selectivity. Top[cs in Catalysis, 2008. 49[3-4]; p. 126-135.

16. Grass, M.E., et al., Silver ion mediated shape control of piatinum nanoparticles: Removal of silver by selective etching jeods to increased catalytic activity. Journal of Physical Chemistry C, 2008. 112(13): p. 4797-4804.

17. Rioux, R.M., et al., Monodisperse platinum nanoparticles of well-defined shape: synthesise charocterization, catolytic properties and future prospects. Topics in Catalysis, 2006. 39[3-4]: p. $167: 174$.

18. Grass, M.E., et al., Colloidally Synthesized Monodisperse Rh Nonoparticles Supported on SBA-15 for Size-and Pretreatment-Dependent Studies of CO Oxidation. Journal of Physical Chemistry $\mathrm{C}$, 2009. 113(20): p. 8616-8623.

19. Somorjai, G.A. and J.Y. Park, Molecular Factors of Catalytic Selectivity. Angewandte ChemieInternational Edition, 2008. 47(48): p. 9212-9228.

20. Heiz, U. and U. Landman, Nanocatalysis. Nanoscience and technology, 2007, Berlin; New York: Springer. xvi, $503 \mathrm{p}$.

21. Somorjai, 6.A. and C.J. Kliewer, Reaction selectivity in heterogeneous catolysis. Reaction Kinetics and Catalysis Letters, 2009. 96(2): p. 191-208.

22. Bond, G.C. and D.T. Thompson, Catalysis by gold. Catalysis Reviews-Science and Engineering, 1999. 41(3-4): p. 319-388. 
23. Bell, A.T., The impact of nanoscience on heterogeneous catolysis. Science, 2003. 299(5613): p. 1688-1691.

24. Harding, $C_{\text {, }}$, et al., Control and Manipulation of Gold Nanocatolysis: Effects of Metal Oxide Support Thickness and Composition. Joumal of the American Chemical Society, 2009. 131(2): p. 538-548.

25. Wel, J.M. and E. Iglesia, Structural and mechanistic requirements for methane activation and chemical conversion on supported iridium clusters. Angewandte Chemie-International Edition, 2004. 43(28): p. 3685-3688.

26. Zhang, J., et al., Surface-modified carbon nanotubes catalyze oxidative dehydragenation of nbutane. Science, 2008. 322(5898): p. 73-77.

27. Centi, G. and S. Perathoner, The Role of Nanostructure in Improving the Performance of Electrodes for Energy Storoge and Conversion. European Journal of Inorganic Chemistry, 2009. 26(26): p. 3851-3878.

28. Zhao, H.B., et al., Metal chlorides in ionic liquid solvents convert sugars to 5 hydroxymethyifurfural. Science, 2007. 316[5831]: p. 1597-1600.

29. Rinaldi, R., R. Palkovits, and F. Schuth, Depolymerization of Cellulose Using Solid Catalysts in Ionic Liquids. Angewandte Chemie-International Edition, 2008. 47(42): p. 8047-8050.

30. Hara, M., Biomass conversion by a solid acid catalyst. Energy Environ. Sci., 2010. 3: p. 601-607.

31. Onda, A., T. Ochi, and K. Yanagisawa, Selective hydrolysis of cellutose into glucose over solid acid catalysts. Green Chemistry, 2008. 10(10): p. 1033-1037.

32. Yan, $\mathrm{N}$, et al., One-step conversion of cellobiose to $\mathrm{C}-6$-aicohols using a ruthenium nanocluster cotalyst. Journal of the American Chemical Society, 2006. 128[27]: p. 8714-8715.

33. Koszinowski, $K, 0$. Schroder, and $\mathrm{H}$. Schwar, Reactivity of small cationic platinum ciusters. Journal of Physical Chemistry A, 2003. 107(25): p. 4999-5006.

34. Lang, S.M., et al., Methane Activation and Cotalytic Ethylene Formation on Free Au-2( + ). Angewandte Chemie-International Edition, 2010. 49(5): p. 980-983.

35. Crossley, S., et al., Solla Nanoparticles that Catalyze Blofuel Upgrade Reuctions at the Water/OH interfoce. Science, 2010. 327(5961): p. 68-72.

36. Carlini, $C_{1}$, et al., Selective oxidation of 5-hydroxymethyl-2-furaldehyde to furan-2,5dicarboxaldehyde by catolytic systems bosed on vonadyl phosphote. Applied Catalysis a-General, 2005. 289(2): p. 197-204.

37. Budroni, G. and A. Corma, Goid and gold-platinum as active and selective catalyst for biomoss conversion: Synthesis of gamma-butyrolactone and one-pot synthesis of pyrrolidone. Jaurnal of Catalysis, 2008. 257(2): p. 403-408.

38. Casanova, O., S. Iborra, and A. Corma, Biomoss into Chemicals: Aerobic Oxidation of 5 Hydroxymethyl-2-furfural into 2,5-Furandicarboxylic Acid with Gold Nanoparticie Catalysts. Chemsuschem, 2009. 2(12): p. 1138-1144.

39. Bianchi, C.L., et al., Selective oxidation of glycerol with oxygen using mana and bimetallic catalysts based on Au, Pd and Pt metals. Catalysis Today, 2005. 102; p. 203-212.

40. Kuhn, J.N., et al., Structure Sensitivity of Carbon-Nitrogen Ring Opening: Impact of PIatinum Particle Size from below I to $5 \mathrm{~nm}$ upon Pyrrole Hydrogenation Product Selectivity over Monodisperse Platinum Nanoparticles Loaded onto Mesoporous Silica. Journal of the American Chemical Society, 2008. 130(43): p. 14026-+.

41. Tsung, C.K., et al., Sub-10 nm Plotimum Nanocrystois with Size and Shope Control: Catalytic Study for Ethylene and Pyrrole Hydrogenation. Journal of the American Chemical Society, 2009. 131(16): p. 5816-5822.

42. Sinfelt, J.H., Role of surface science in catolysis. Surface Science, 2002. 500(1-3): p. 923-946. 
43. Norskov, J.K., et al., The noture of the octive site in heterogeneous metol catolysis. Chemical Society Reviews, 2008. 37(10): p. 2163-2171.

44. Norskov, J.K., et al., Towards the computational design of solid catalysts. Nature Chemistry, 2009. 1(1): p. 37-46.

45. Sinfelt, J.H., G.H. Via, and F.W. Lytle, APPLICATION OF EXAFS N CATALYSIS - STRUCTURE OF EMMETALLIC CLUSTER CATALYSTS. Catalysis Rev|ews-Stience and Eng|neering, 1984, 26(1): p. 81140.

46. Studt, $\mathrm{F}_{\text {. }}$ et al., Identification of non-precious metal alloy cotalysts for selective hydrogenation of acetylene. Science, 2008, 320(5881): p. 1320-1322.

47. TaO, $\mathrm{F}_{4}$ et al., Reaction-Driven Restructuring of Rh-Pd and Pt-Pd Core-Shell Nonoporticles. Science, 2008. 322(5903): p. 932-934.

48. Joo, S.H., et al., Thermolly stable Pt/mesoporous silica core-shell nanocatalysts for hightemperoture reactions. Nature Materials, 2009. \$(2): p. 126-131.

49. Shen, M. and D.E. Resasco, Emuisions Stabilized by Carbon Nanotube-Silica Nanohybrids. Langmuir, 2009. 25(18): p. 10843-10851.

50. Dresselhaus, M.S. and I.L. Thamas, Altemative energy technologies. Nature, 2001. 414(6861): p. 332-337.

51. Hochbaum, A.I. and P.D. Yang, Semiconductor Nanowires for Energy Conversion. Chemical Reviews, 2010. 110[1): p. 527-546.

52. Kamat, P.V., Meeting the clean energy demand: Nanostrutture architectures for solar energy conversion. Journal of Physical Chemistry C, 2007. 111;7): p. 2834-2860.

53. Park, S., et al., $n$-Type silicon quontum dots and $\rho$-type crystolline silicon heteroface solor cells. Solar Energy Materials and Solar Cells, 2009. 93(6-7): p. 684-690.

54. Paxman, M., et al., MOOELING THE SPECTRAL RESPONSE OF THE QUANTUM-WELL SOLAR-CELL. Journal of Applied Physics, 1993. 74\{1\}: p. 614-621.

55. Yum, J.H., et al., Recent Developments in Solid-State Dye-Sensitized Solar Cells. Chemsuschem, 2008. 1(8-9): p. 699-707.

56. Hardin, B.E., et al., Incredsed light harvesting in dye-sensitized solar cells with energy reloy dyes. Nature Photonics, 2009. 3(7): p. 406-411.

57. Nozik, Ad., Multiple exciton generction in semiconductor quantum dots. Chemical Physics Letters, 2008. 457(1-3): p. 3-11.

58. Gratzel, M., Solar energy conversion by dye-sensitized photovoltoic cells. Inorganic Chemistry, 2005. 44(20): p. 6841-6851.

59. Gratzel, M., Photoelectrochemical tells. Nature, 2001. 414(6861): p. 338-344.

60. Bak, T., et al., Photo-electrochemicol hydrogen generotion from water using solor energy. Materials-related aspects. International Journal of Hydrogen Energy, 2002. 27(10): p. 991-1022.

61. Ni, M., et al, A review and recent developments in photocatolytic woter-splitting using TiO2 for hydrogen production. Renewable \& Sustainable Energy Reviews, 2007. 11(3): p. 401-425.

62. Centi, G. and S. Perathoner, Towards Solar Fuels from Water and CO2. Chemsuschem, 2010. 3(2): p. 195-208.

63. Roy, S.C., et al., Toward Solar Fuels: Photocatolytic Conversion of Carbon Dioxide to Hydrocarbons. Acs Nano, 2010. 4(3): p. 1259-1278.

64. Hisatomi, T., et al, , Aspects of the Water Splitting Mechanism on (Ga1-xZnx)(N1-xOx) Photocotalyst Modified with Rh2-yCryos Cocotolyst. Journal of Physical Chemistry C, 2009. 113(51): p. 21458-21466.

65. Maeda, K., K. Teramura, and K. Domen, Effect of post-caicinotion on photocatalytic activity of (Ga1-xZnx)(N1-xOx) solid solution for overall water splitting under visible light. Joumal of Catalysis, 2008. 254(2): p. 198-204. 
66. Steele, B.C.H. and A. Heinzel, Moteriois for fuel-cell technologies. Nature, 2001. 414(6861): p. 345-352.

67. Winter, M. and R.J. Brodd, What are batteries, fuel cells, and supercopacitors? Chemical Reviews, 2004. 104[10]: p. 4245-4269.

68. Maier, J., Nanoionics: ion transport and electrochemical storage in confined systems. Nature Materlals, 2005, 4(11): p. 805-815.

69. Maier, J., Nonoionics: ionic charge carriers in small systems. Physical Chemistry Chemical Physics, 2009. 11(17): p. 3011-3022.

70. Maekawa, $\mathrm{H}_{\text {, }}$ et al, Size-dependent ionic conductivity observed for ordered mesoporous alumina-Lil composite. Solid State lonics, 2004. 175(1-4): p. 281-285.

71. Aurbach, D., Review of selected electrode-solution interactions which determine the performance of $L$ and $L i$ ion batteries. Journal of Power Sources, 2000. 89[2]: p. 206-218.

72. Salitra, $\mathrm{G}$, et al., Carbon electrodes for double-fayer topocitors - $L$ Relations between ion and pore dimensions. Journal of the Electrochemical Society, 2000. 147(7): p. 2486-2493.

73. Wang, Y. and G.Z. Cao, Developments in nanostructured cathode materials for high-performance fithium-ion botteries. Advanced Materials, 2008. 20[12]: p. 2251-2269.

74. McGreery, R.L., Advanced carbon electrode materials for molecular electrochemistry. Chemical Reviews, 2008. 108(7); p. 2646-2687.

75. Centi, G. and S. Perathoner, Problems and perspectives in nanostructured carbon-bosed electrodes for clean and sustainable energy. Catalysis Today, 2010. 150|1-2): p. 151-162.

76. Venkatasubramanian, R., APPLIED PHYSICS Nanothermal trumpets. Nature, 2010. 463\{7281\}: p. $619 \cdot 619$.

77. Harman, T.C., et al., Quantum dot superlattice thermoelectric moteriols and devices. Science, 2002. 297(5590): p. 2229-2232.

78. Venkatasubramanian, $\mathbf{R}$, et al., Thin-film thermoelectric devices with high room-temperature figures of merit. Nature, 2001. 413(6856): p. 597-602.

79. Bergh, A., et al., The promise and challenge of solid-state lighting. Phys[cs Today, 2001. 54[12]; p. $42-47$.

80. Schubert, E.F. and J,K, Kim, Solid-state light sources getting smart. Science, 2005. 308(5726):p. 1274-1278.

81. Alivisatos, A.P., Perspectives on the physical chemistry of semiconductor nanocrystais. Journal of Physical Chemistry, 1996. 100(31): p. 13226-13239.

82. Kuykendall, T., et al., Complete composition tunability of inGaN nanowires using a combinatorial approoch. Nature Materials, 2007. 6412): p. 951-956.

83. Bhushan, B., Tribology: Friction, Wear, and Lubrication, in The Engineering Hondbook, R.C. Dorf, Editor. 2000, CRC Press LLC: Boca Raton, FL.

84. Bhushan, B., Nanotribology and nanomechanics in nano/biotechnology. Philosophical Transactions of the Royal Society a-Mathematical Physical and Engineering Sciences, 2008. 366 (1870): p. $1499-1537$.

85. Bhushan, B., Nanotribology of corbon nonotubes. Journal of Physics-Condensed Matter, 2008. 20[36].

86. Bhushan, B., J.N. Israelachvili, and U. Landman, NANOTRIBOLOGY - FRICTION, WEAR AND LUBRICATION AT THE ATOMIC-SCALE. Nature, 1995. 374(6523): p. 607-616.

87. Rapoport, L., et al., Hollow nanoporticles of WS2 as potential solid-state lubricants. Nature, 1997. 387(6635): p. 791-793.

88. Chhowalla, M. and G.A.J. Amaratunga, Thin fitms of fullerene-like MoS2 nanoparticles with uitralow friction and wear. Nature, 2000. 407(6801): p. 164-167. 
89. Zheng, H.M., et al., Observation of Single Colloidal PIatinum Nanocrystal Growth Trajectories. Science, 2009. 324(5932): p. 1309-1312.

90. Polte, J., et al., Nucleation and Growth of Gold Nanoparticles Studied via in situ Small Angle X-ray Scattering at Milisecond Time Resolution. Acs Nano, 2010. 4(2): p. 1076-1082.

91. Finney, E.E. and R.G. Finke, Nanociuster nucieation and growth kinetic and mechanistic studies: A review emphosizing tronsition-metal nanoclusters. Journal of Collold and Interface Sclence, 2008. 317(2): p. 351-374.

92. Murray, C.B., Wotching Nanacrystals Grow. Science, 2009. 324/5932)* p. 1276-1277. 


\section{LEGAL DISCLAIMER}

This document was prepared as an account of work sponsored by the United States Government. While this document is believed to contain correct information, neither the United States Government nor any agency thereof, nor The Regents of the University of California, nor any of their employees, makes any warranty, express or implied, or assumes any legal responsibility for the accuracy, completeness, or usefulness of any information, apparatus, product, or process disclosed, or represents that its use would not infringe privately owned rights. Reference herein to any specific commercial product, process, or service by its trade name, trademark, manufacturer, or otherwise, does not necessarily constitute or imply its endorsement, recommendation, or favoring by the United States Government or any agency thereof, or The Regents of the University of California. The views and opinions of authors expressed herein do not necessarily state or reflect those of the United States Government or any agency thereof or The Regents of the University of California. 